\title{
Physiologic and hematologic concerns of rotary blood pumps: what needs to be improved?
}

\author{
Tohid Pirbodaghi $\cdot$ Siavash Asgari $\cdot$ \\ Chris Cotter $\cdot$ Kevin Bourque
}

Published online: 3 April 2013

(c) Springer Science+Business Media New York 2013

\begin{abstract}
Over the past few decades, advances in ventricular assist device (VAD) technology have provided a promising therapeutic strategy to treat heart failure patients. Despite the improved performance and encouraging clinical outcomes of the new generation of VADs based on rotary blood pumps (RBPs), their physiologic and hematologic effects are controversial. Currently, clinically available RBPs run at constant speed, which results in limited control over cardiac workload and introduces blood flow with reduced pulsatility into the circulation. In this review, we first provide an update on the new challenges of mechanical circulatory support using rotary pumps including blood trauma, increased non-surgical bleeding rate, limited cardiac unloading, vascular malformations, end-organ function, and aortic valve insufficiency. Since the non-physiologic flow characteristic of these devices is one of the main subjects of scientific debate in the literature, we next emphasize the latest research regarding the development of a pulsatile RBP. Finally, we offer an outlook for future research in the field.
\end{abstract}

\section{T. Pirbodaghi}

Graduate School for Cellular and Biomedical Sciences,

University of Bern, Bern, Switzerland

T. Pirbodaghi $(\bowtie)$

ARTORG Cardiovascular Engineering, University of Bern,

Murtenstrasse 50, 3010 Bern, Switzerland

e-mail: pirbodaghi@artorg.unibe.ch

T. Pirbodaghi $\cdot$ C. Cotter $\cdot$ K. Bourque

Thoratec Corporation, Burlington, MA, USA

S. Asgari

Department of Surgery-Cardiac Section, School of Medicine,

Yale University, New Haven, CT, USA
Keywords Ventricular assist devices - Rotary blood pumps $\cdot$ Heart failure $\cdot$ Continuous flow $\cdot$ Pulsatile flow

\section{Introduction}

A ventricular assist device (VAD) is a mechanical pump that helps to improve blood circulation in patients with a weakened ventricle. It typically draws blood from the apex of the left ventricle (LV) and pumps it into the circulation through the ascending aorta (Fig. 1). DeBakey [1] introduced the first successful clinical applications in the 1960s. After three decades of improvement, in the mid-1990s, they became an established treatment option for heart failure patients awaiting transplant as a bridge to transplantation (BTT) [2]. VADs can also provide long-term mechanical support as destination therapy (DT) and in a relatively small number of cases with non-ischemic etiology lead to improved cardiac function, or so-called reverse remodeling as a bridge to recovery. The first generation of VADs was based on a pneumatically or electrically driven volume displacement pump (Figs. 2a, 3). Due to the working principle analogous to the native heart with filling (diastole) and ejection (systole) phases, they provide excellent hemodynamic support. Nonetheless, their applications have substantial constraints because of their large size, invasive surgical procedure, and poor durability for long-term mechanical support [3]. These challenges necessitated the development of a new generation of VADs with simple design and improved performance.

Over the past two decades, the advent of rotary blood pumps (RBPs) as assist devices has revolutionized the field of mechanical circulatory support due to their small size (Fig. 2), silent operation, and long-term durability. Rotary pumps consist of only one moving part, the rotor, and are 


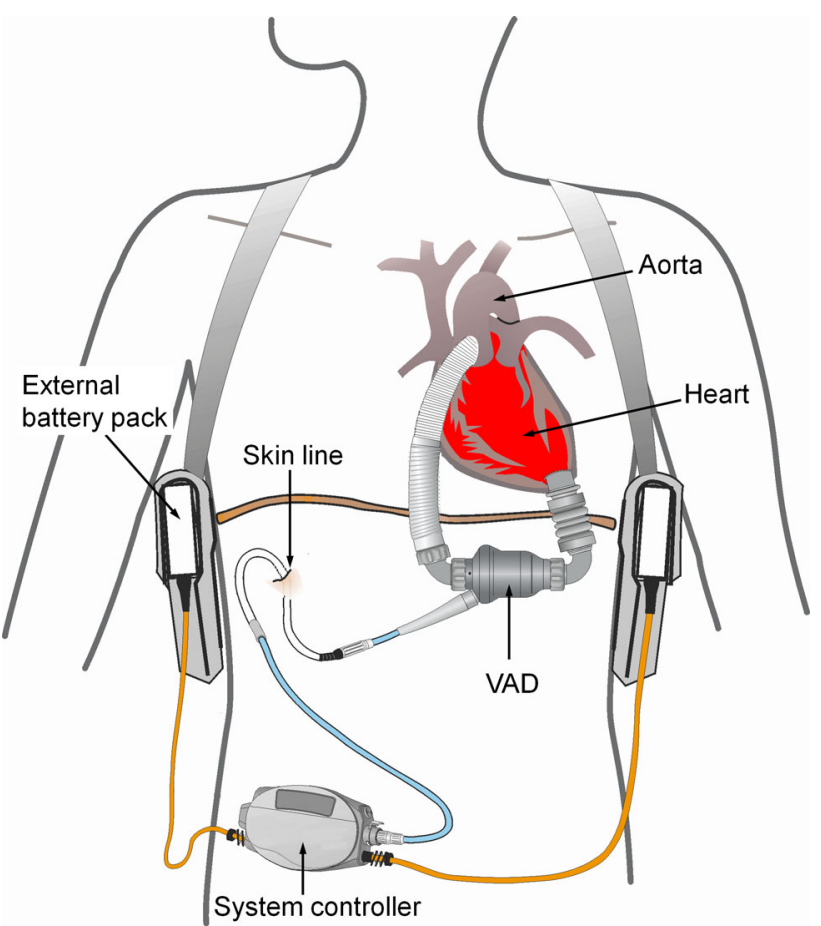

Fig. 1 The schematic of an implanted VAD and its components, courtesy of Thoratec Corporation

divided into two main categories: (1) axial flow pumps and (2) magnetically or hydro-dynamically levitated centrifugal pumps (Fig. 4). On the one hand, their operating mechanism makes it possible to achieve a reliable and durable device; on the other hand, it reduces the blood flow pulsatility owing to typical use of constant speed in clinically

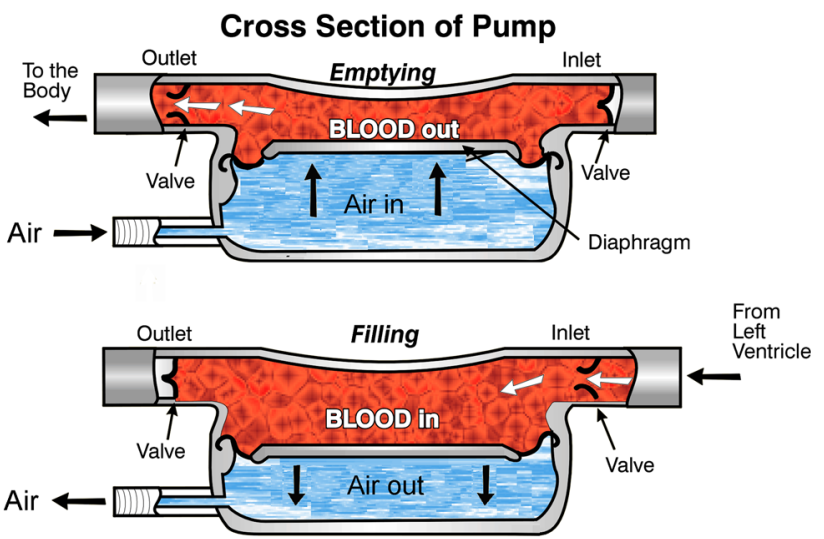

Fig. 3 The schematic of a pneumatic pulsatile VAD cross-section, courtesy of Thoratec Corporation

available devices. Despite improvements in clinical outcomes and advantages over pulsatile pumps, fundamental questions persist particularly about unknown physiologic effects of reduced arterial pulsatility in a milieu of tolerable but persisting adverse events.

Here, we first focus on the current challenges of RBPs. Then, we review recent attempts to develop a pulsatile rotary pump, and finally, we offer an outlook for further research.

\section{Emerged concerns}

Although adverse events, including surgical mortality, right ventricular failure, neurological events, and infections, as
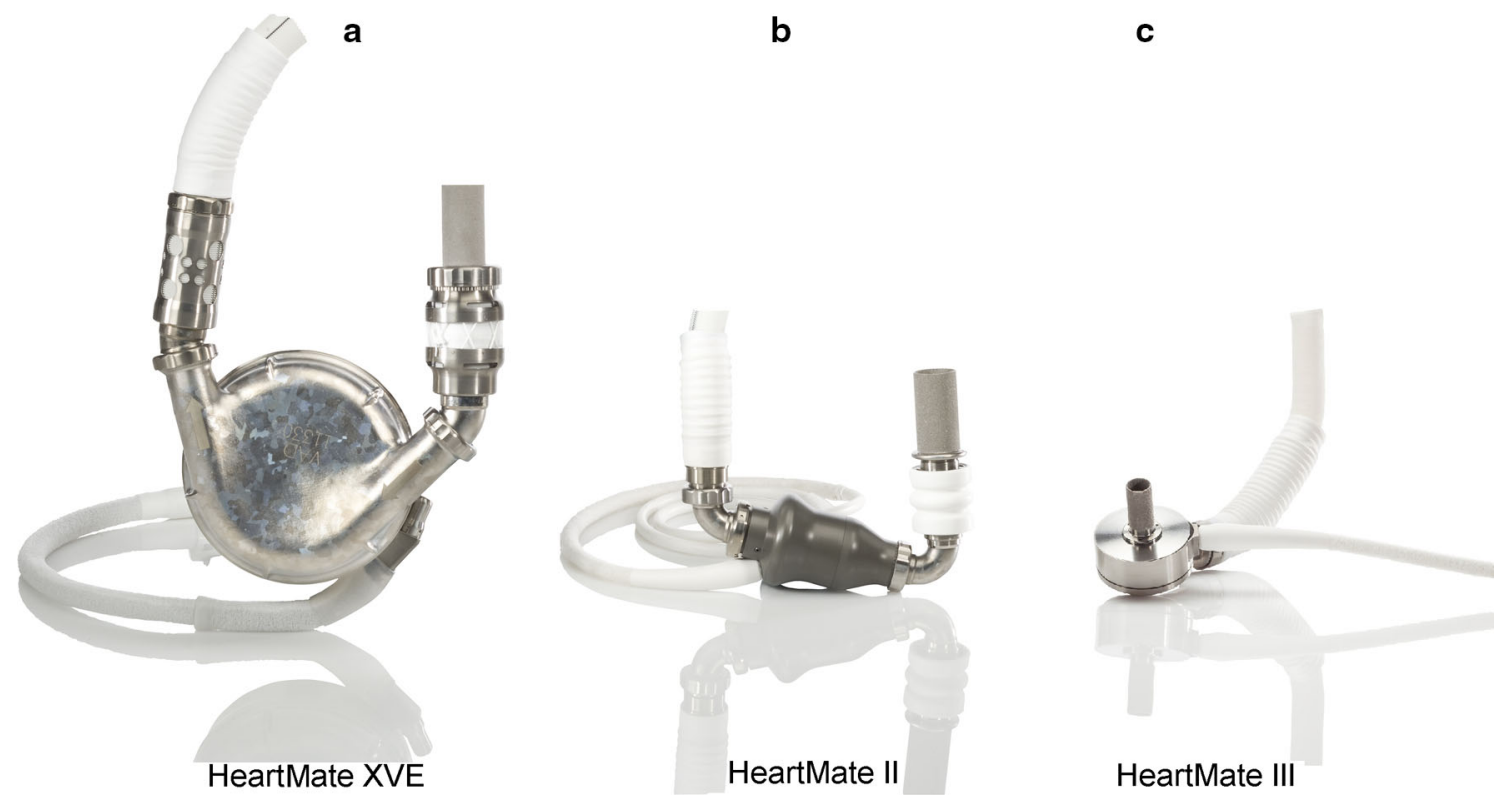

Fig. 2 Different types of blood pumps. a HeartMate XVE (volume displacement pump), b HeartMate II (axial rotary pump), c HeartMate III (centrifugal rotary pump), courtesy of Thoratec Corporation 
Fig. 4 a Components of an axial flow rotary blood pump, b components of a centrifugal rotary blood pump, courtesy of Thoratec Corporation
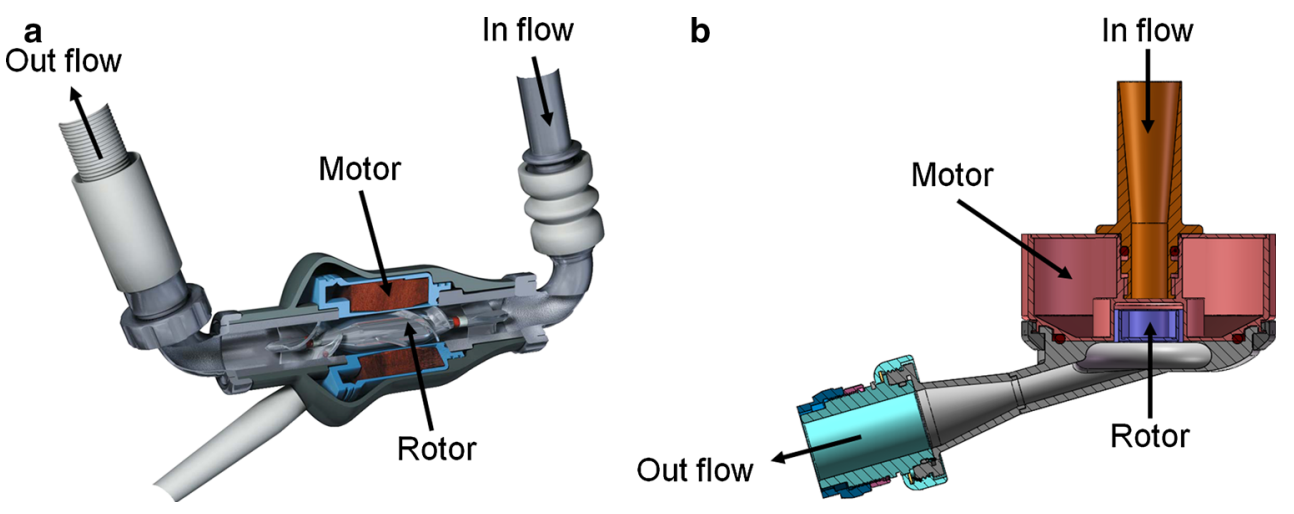

with pulsatile devices, still persist for rotary pumps, in this section, we only focus on concerns related to working mechanism of RBPs. These include blood trauma, increased rate of non-surgical bleeding, limited cardiac unloading, vascular malformations, end-organ function, and aortic valve insufficiency.

\section{Blood trauma}

Depending on the design, miniaturized RBPs might reach rotational speeds $(\omega)$ higher than 30,000 revolutions per minute to supply enough blood flow. Upon passage through the pump, blood cells and proteins are exposed to very brief durations of high shear stress level of about 1,000 $\mathrm{Pa}$ (unpublished data), which are possible sources of damage to blood particles. Although the exact hematologic effects of RBPs have not been completely investigated, elevated shear forces play an important role in the incidence of thromboembolism. It is widely recognized that platelets together with a plasma protein, von Willebrand factor (vWF), play an essential role in both thrombus formation and hemostasis. Increased shear forces disturb the normal distribution of vWF molecules and may result in acquired von Willebrand syndrome. According to Sheriff et al. [4], platelets exposed to high shear stress for a short time are sensitized to subsequent lower values and activate at least 20-fold faster than particles under standard circulation conditions. Platelets and white blood cells are sensitive to mechanical stress at levels of 10 and $7.5 \mathrm{~Pa}$, respectively, whereas red blood cells are less sensitive with high level of a few hundred $\mathrm{Pa}$ [5]. However, exposure time to mechanical force is critical for the maximum shear stress tolerable by cells. For example, $800 \mathrm{~Pa}$ with an exposure duration of $1 \mathrm{~ms}$ has been reported as the hemolytic threshold [6]; whereas another study shows that by increasing the exposure time to $700 \mathrm{~ms}$, hemolysis occurs at shear stress of $255 \mathrm{~Pa}$ [7]. It should be noted that in normal vascular blood flow, the maximum shear stress is approximately $6 \mathrm{~Pa}$ occurring in the wall of arterioles [8]. These data show that devices designed based on only hemolysis tests are not optimized to reduce thrombogenicity due to high mechanical forces.

Furthermore, elevated shear stress enhances the shedding of various microparticles (MPs) from blood cells, as well as endothelial cells into circulation. These submicron particles, which are components of cells plasma membranes and bear membrane proteins of their mother cell, play an essential biologic role in inflammation, vascular injury, angiogenesis, and thrombosis [9]. A recent research study by Diehl et al. [10] demonstrates that VAD patients have elevated levels of circulating MPs, which may contribute to the occurrence of thromboembolic complications. While MPs have important physiologic and pathologic roles, their contributions to the side effects of RBPs remain unexplored. Further details about hematologic effects of RBPs are found in previous publications [11, 12].

\section{Bleeding}

Increased non-surgical bleeding, specifically in the gastrointestinal (GI) tract, is one the most frequent adverse events associated with RBPs [13]. In 2005, Letsou et al. [14] were the first to report 3 cases of GI bleeding after implantation of the Jarvik 2000 in 21 patients. By reviewing 101 VAD recipients (55 rotary and 46 pulsatile pumps), Crow et al. [15] reported almost 10-fold increases in the incidences of GI bleeding in rotary versus pulsatile devices. Additionally, based on long-term clinical studies performed between 2003 and 2011, there is sufficient evidence to demonstrate higher rates of GI bleeding event in patients supported with axial and centrifugal rotary pumps, which was not the case for patients receiving pulsatile devices [16, 17].

In an interesting study, Uriel et al. [18] tried to identify potential mechanisms for those bleeding events and investigated vWF multimers in rotary pump patients. They observed a reduction in vWF multimers of 31 patients, whereas only 18 of them (58\%) experienced bleeding. Their finding is supported by other studies that show significant loss of vWF multimers in RBP recipients, but only 
some patients had bleeding complications $[19,20]$. A similar problem of an acquired form of von Willebrand syndrome with subsequent bleeding has been reported in patients with aortic stenosis [21]. Taken together, increased pressure inside blood vessels, high shear stress, and low pulse pressure were suggested as potential explanations for von Willebrand disease [15]. These findings indicate that loss of vWF multimers alone cannot predict bleeding risk. Although the biology and mechanism behind the bleeding is not completely understood, its higher rate associated with RBP recipients makes it rational to draw the conclusion that (1) the high-speed rotor causes damage to blood particles or (2) attenuated pulsatility plays an important role. Further research is required to identify risk factors for bleeding in these patients.

\section{Limited cardiac unloading}

A promising application of VADs besides their usage in the BTT and DT is as a bridge to myocardial recovery [22]. It was first reported by Levin et al. [23] in 1996, who found a considerable functional and structural improvement in the failing heart of a young patient after 6 months of support. It is likely that mechanical unloading stimulates the cellular biology of the myocardium and initiates recovery by alleviating the cardiac workload and relieving the biomechanical stress imposed on the cardiomyocytes [24]. Cardiac unloading is also associated with improvements in matrix metalloproteinase activity, myocyte calcium handling, and neurohormonal stimulation [25]. However, the precise mechanism by which a failing heart recovers is not completely clear.

By conducting studies on explanted human hearts, Levin et al. [26] demonstrated that ventricular dilation because of chronic cardiomyopathy could be largely reversed after 3-5 months of mechanical support. Their finding was supported by Altemose et al. [27] who observed reductions in LV chamber size and a $40 \%$ decrease in LV mass in eight patients. The cellular basis for these changes was discussed by Zafeiridis et al. [28] who examined isolated cardiac myocytes from VAD-supported and non-supported failing hearts as well as healthy hearts. They observed that mechanical support resulted in a $28 \%$ reduction in myocyte volume and $20 \%$ reduction in cell length and width. In addition, myocyte contractility and its rates of shortening and relengthening improve within 3 months of circulatory support [29]. These findings indicate that cardiac workload is a major factor in pathologic cardiac hypertrophy and remodeling. Thus, mechanical unloading, which is associated with reduced wall stress, leads to favorable alterations in geometry at the organ and cellular levels of a failing heart.
A series of clinical studies demonstrates that volume displacement pumps are associated with greater LV unloading in heart failure patients compared with rotary pumps [30, 31]. This is consistent with data from animal experiments demonstrating that pulsatile pumps provide superior LV unloading and maintain a better physiologic stability [32]. This limitation of RBPs arises mainly because clinically available devices typically operate at constant speed mode confining their operating range by suction and regurgitation events. An excessive constant pump speed results in ventricular collapse, and too low speed leads to back flow of blood into the ventricle increasing cardiac workload.

Vascular malformations

Blood vessels are compliant structures that respond to physiologic conditions in terms of geometrical, structural, and functional adaptations. These adaptations are mediated in part by the vascular endothelial cells (ECs), which are directly exposed to blood flow and associated shear stress. The ECs respond to the biomechanical forces in terms of molecular signaling, gene expression, and functional changes [33]. Under normal blood flow and physiologic conditions, the fluid-induced forces are mechanotransduced into biochemical signals that result in vascular caliber regulations as well as inhibition of thrombosis and inflammation of the vessel wall. However, little is known about the impact of alterations in flow patterns and mechanical forces on ECs and vascular function in RBP patients.

In a clinical study of 20 VAD patients, Amir et al. [34] found lower endothelial function in conduit arteries and impaired peripheral vascular reactivity, most likely owing to reduced pulsatility. Westaby et al. [35] reported a decrease in medial aortic thickness and medial smooth muscle cell (SMC) number after 3 months of support with Jarvik 2000 RBP in 7 patients. SMCs play a critical role during atherogenesis, which is the developmental process of atheromatous plaques and is characterized by remodeling of arteries leading to accumulation of plaques. Other clinical studies also provide enough evidence of arteriovenous malformation highly associated with flow characteristics of RBPs [14, 16]. These clinical observations are further confirmed in animal studies where thinner aortic and arterial walls as well as a lower volume ratio of SMCs were claimed due to decreased pulsatility [36].

Furthermore, prolonged circulatory support using RBPs significantly decreases vascular pulsatility, diminishes the constrictive function of the vascular system, and increases peripheral vascular resistance, which can augment the load on the $\operatorname{LV}[36,37]$. As a result, decreased pulse pressure and changes in blood flow pattern will lead to undesirable 
morphological changes of aortic and arterial walls, as well as vascular surfaces, in particular, in locations such as the descending thoracic aorta and distal carotid arteries.

\section{End-organ function}

As early as the 1950s, shortly after the development of cardiopulmonary bypass, there was a substantial debate about whether the non-pulsatile perfusion provides adequate blood flow to maintain proper end-organ function $[37,38]$. These early studies together with cardiopulmonary bypass experience during the last few decades suggest that short-term non-pulsatile flow is well tolerated. After the advent of rotary pumps, end-organ perfusion was a great concern; thus, many investigators examined this issue in animal models. Saito et al. [39] demonstrated that use of RBPs for a few months maintained normal end-organ function and reported no histologic abnormalities of the brain, liver, and kidney. By contrast, a number of animal experiments have shown variations in skin tissue microcirculation as well as microcirculation of the kidney and liver, including retention of blood cells, expansion of the proximal tubes, and glomerulus blood capillaries, but there is no evidence that these histologic changes impair endorgan function [40, 41]. What is more, the clinical relevance of their outcome can be ambiguous because of the use of healthy animals.

In humans, although insufficient data exist about the effects of attenuated pulsatility on end-organ function within a few years, clinical studies have shown that renal, hepatic, and neurocognitive functions are maintained within a normal range for durations up to 15 months $[42,43]$. The comparison of renal and hepatic functions in patients who received a VAD as a BTT shows no major difference between continuous and pulsatile flow devices [44]. Regarding endocrine functions, there is no major effect of reduced pulsatility on the hypothalamic-pituitary end-organ system and sympathoadrenal functions [45]. Results of a study by Polska et al. [46] showed that alterations in flow pulsatility had only a small influence on blood flow in the choroid and mean flow velocities in the ophthalmic artery. In another clinical study, Kamdar et al. [47] compared the effects of centrifugal, axial, and pulsatile VADs on end-organ function for up to 3 months; their finding is consistent with recent reports by Slaughter [42] and Russell et al. [48], suggesting that RBPs supply sufficient end-organ perfusion, at least for a relatively short time support. In a recent publication, Chokshi et al. [49] provided new insight into cardiac metabolism in heart failure patients suggesting that mechanical support improves systemic and local metabolic derangements in VAD patients. This may reduce myocardial levels of toxic lipid intermediates and improve cardiac insulin signaling.
It should be noted that under most clinical conditions, RBP patients have some degree of arterial pulsatility due to native ventricular contractions. Further long-term studies preferably in randomized clinical trials are crucial to assess the effect of reduced pulsatility on pulmonary function, microcirculatory system, neuroendocrine markers, and cerebral blood flow, or metabolism.

\section{Aortic valve insufficiency}

One unexpected complication of mechanical circulatory support is the development of aortic valve lesions, which may result in commissural fusion and aortic valve insufficiency (AI). Depending on the degree of LV unloading by $\mathrm{VAD}$, the aortic valve remains partially or completely closed, which increases the mechanical stress on the valve. These forces affect valvular endothelial and interstitial cells and may result in valve remodeling or pathologic alterations [50]. In addition, changes in aortic blood flow dynamics and myxoid degeneration of the aortic valve were suggested to contribute to AI development and progression [51]. AI impairs the VAD function, increases the risk of thromboembolism events, and is a great concern in potential bridge to recovery patients. Although this complication was reported during support by volume displacement pumps [52], recent studies suggest that $\mathrm{AI}$ is more prevalent among RBP recipients [53, 54]. Intermittently lowering the pump speed, which allow opening of the aortic valve during systole, was suggested to reduce the risk of thrombus formation in the aortic root and prevent leaflet fusion [55]. A better understanding of the RBP impact and the relationship between mechanics and valve biology will provide insights into the pathophysiology of aortic valve disease. A recent publication by John et al. [50] describes the basis for structural changes and discusses different techniques of aortic valve management during VAD support in more detail.

\section{Towards a pulsatile rotary blood pump}

As controversy remains on the long-term effects of perfusion with reduced pulsatility, speed modulation of the pump might be beneficial to restore vascular pulsatility. Besides its effect on reducing complications potentially tied to reduced arterial pulsatility, speed modulation of RBPs can effectively control cardiac workload [56, 57], which is likely important for heart recovery and device weaning. Moreover, the introduction of pulsatile RBPs would provide a unique opportunity for further research and comparison. In the literature, there are few reports describing the attempts to modulate the rotary pump's speed, which only focus on asynchronous speed 
modulation [58], mathematical modeling [59], and in vitro investigation of pump speed modulation using mostly sinusoidal waveforms [60].

Bourque et al. [61] evaluated the impact of a pulsatile centrifugal pump on an ovine thoracic and abdominal aortic flow and pressure. To eliminate all native cardiac contributions to pulsatility, they replaced both ventricles with HeartMate III blood pumps. Pulsatile flow was achieved by sharply alternating the speed of the magnetically levitated rotor of the left pump between 1,500 rpm (diastole) and 5,500 rpm (systole) at a rate of $60 \mathrm{bpm}$ and a systolic period of $30 \%$. Results showed that the mean pump-induced pulse pressure was $34 \mathrm{mmHg}$ in the ascending aorta and the maximum rate of pressure rise ( $\delta p /$ $\delta t$ ) was between 189 and $238 \mathrm{mmHg} / \mathrm{s}$, approaching that of the native pulse. Ando et al. [62] studied the effect of speed modulation of the EvaHeart RBP on myocardial perfusion in an animal model and reported an increase in coronary flow compared with the continuous mode. According to Pirbodaghi et al. [56, 57], pump speed modulation synchronized with the native heart can significantly influence myocardial energy as well as volume. Their findings indicate that high pump speed during diastole has a maximal unloading effect on LV, whereas high speed during systole increases the pulse pressure. Moreover, cardiac stroke work in the pulsatile mode could be reduced to $72 \%$ of that in constant speed indicating the importance of the synchrony between the heart and assist device on LV unloading.

Furthermore, the controllers of some commercially available pumps (e.g. Jarvik 2000, Medos Delta stream DP3, Heartware HVAD) vary the pump speed intermittently and asynchronously to modulate the pump flow and allow better washing. Despite these initial steps toward pulsatile RBPs, more studies are required to explore the concept, determine its efficiency, and assess the importance of different prescriptive parameters.

\section{Future considerations}

While RBPs are rapidly evolving to provide destination therapy as an alternative to heart transplantation, many fundamental questions pertaining to their operating mechanisms remain to be addressed. How does the attenuated pulsatility with RBPs affect cell-cell interactions within the blood flow stream? What is its impact on blood cells margination from the center of a blood vessel toward the vascular endothelium, in particular, white blood cells that are important in the inflammatory response? How does elevated shear stress influence gene expression, extracellular and intracellular matrices? What is the impact of partial or complete unloading on myocardial blood flow and metabolism? Is there a degree of pulsatility or unloading, which may optimize myocardium recovery? In this regard, the use of combination therapies that consist of mechanical unloading and pharmacologic or biologic therapies can promote recovery in a large number of patients. It is widely known that treatment with betablockers and ACE inhibitors during mechanical support increases the probability of cardiac recovery. There is also preliminary evidence that stem cells from percutaneous endomyocardial biopsy specimens promote cardiac regeneration and improve heart function [63].

Among other issues, abdominal driveline infection is a major concern for long-term mechanical support, as with all VADs that have a percutaneous component [64]. Current alternatives include a transcutaneous energy transfer system (TETS) [65] to wirelessly power implantable devices and skull pedestal power delivery techniques [66]. The former has poor efficiency and suffers from technical concerns [67]; the latter requires an invasive surgery process and is associated with a low quality of life. Thus, it is necessary to develop more effective and reliable power delivery systems. Recent studies $[67,68]$ on wireless power transfer based on the free-range resonant electrical delivery (FREE-D) appear promising, but more research needs to be conducted in this area.

While platelet activation is critically correlated with high shear stress, its aggregation is more likely to happen at low stress levels [69], indicating that areas of stasis within the device might contribute to thrombosis formation. Thus, it is critical to identify low and high threshold stresses and completely understand the fluid dynamics of the blood inside RBPs as well as in the inflow/outflow conduits. Furthermore, platelet adhesion and thrombus formation are highly sensitive to exposed foreign surfaces. Despite advances in materials with anticoagulant function, such as heparin and hirudin, there is still no surface coating capable of completely inhibiting thrombus formation. Currently, the inlet and outlet elbows of VADs are textured to entrap particles from the blood and form a biologic coating. To eliminate the need for long-term anticoagulant therapy, which increases the incidence of side effects, the development of new antithrombogenic biomaterials is necessary for the blood-contacting surfaces of the pump and cannulas. Owing to nonthrombogenic properties of endothelial cells (ECs), coating with ECs can pave the way toward a totally nonthrombogenic surface. More investigations are needed to understand the complex molecular structures and interactions between ECs and device surfaces.

Conflict of interest Tohid Pirbodaghi, Chris Cotter, and Kevin Bourque are R\&D researchers at Thoratec Corporation in Burlington, MA, USA. The authors have no financial or personal relationships that could inappropriately influence or bias this work. 


\section{References}

1. DeBakey ME (2000) The Odyssey of the artificial heart. Artif Organs 24:405-411

2. Aggarwal S, Pagani FD (2010) Bridge to transplantation: current outcomes. J Card Surg 25:455-461

3. Caccamo M, Eckman P, John R (2011) Current state of ventricular assist devices. Curr Heart Fail Rep 8:91-98

4. Sheriff J, Bluestein D, Girdhar G, Jesty J (2010) High-shear stress sensitizes platelets to subsequent low-shear conditions. Ann Biomed Eng 38:1442-1450

5. Hellums J (1994) 1993 Whitaker lecture: biorheology in thrombosis research. Ann Biomed Eng 22:445-455

6. Lu PC, Lai HC, Liu JS (2001) A reevaluation and discussion on the threshold limit for hemolysis in a turbulent shear flow. J Biomech 34:1361-1364

7. Wurzinger LJ, Opitz R, Blasberg P, Schmid-Schonbein H (1985) Platelet and coagulation parameters following millisecond exposure to laminar shear stress. Thromb Haemostat 54:381-386

8. Hathcock JJ (2006) Flow effects on coagulation and thrombosis. Arterioscler Thromb Vasc Biol 26:1729-1737

9. Sinning J-M, Losch J, Walenta K, Böhm M, Nickenig G, Werner N (2011) Circulating CD31+/Annexin V+ microparticles correlate with cardiovascular outcomes. Eur Heart J 32:2034-2041

10. Diehl P, Aleker M, Helbing T, Sossong V, Beyersdorf $\mathrm{F}$, Olschewski M et al (2010) Enhanced microparticles in ventricular assist device patients predict platelet, leukocyte and endothelial cell activation. Interact Cardiovasc Thorac Surg 11:133-137

11. Eckman PM, John R (2012) Bleeding and thrombosis in patients with continuous-flow ventricular assist devices. Circulation 125:3038-3047

12. Slaughter M (2010) Hematologic effects of continuous flow left ventricular assist devices. J Cardiovasc Transl Res 3:618-624

13. Pagani FD, Miller LW, Russell SD, Aaronson KD, John R, Boyle AJ et al (2009) Extended mechanical circulatory support with a continuous-flow rotary left ventricular assist device. J Am Coll Cardiol 54:312-321

14. Letsou GV, Shah N, Gregoric ID, Myers TJ, Delgado R, Frazier OH (2005) Gastrointestinal bleeding from arteriovenous malformations in patients supported by the Jarvik 2000 axial-flow left ventricular assist device. J Heart Lung Transplant 24:105-109

15. Crow S, John R, Boyle A, Shumway S, Liao K, Colvin-Adams M et al (2009) Gastrointestinal bleeding rates in recipients of nonpulsatile and pulsatile left ventricular assist devices. J Thorac Cardiovasc Surg 137:208-215

16. Demirozu ZT, Radovancevic R, Hochman LF, Gregoric ID, Letsou GV, Kar B et al (2011) Arteriovenous malformation and gastrointestinal bleeding in patients with the HeartMate II left ventricular assist device. J Heart Lung Transplant 30:849-853

17. Morgan JA, Paone G, Nemeh HW, Henry SE, Patel R, Vavra J et al (2012) Gastrointestinal bleeding with the HeartMate II left ventricular assist device. J Heart Lung Transplant 31:715-718 The official publication of the International Society for Heart Transplantation

18. Uriel N, Pak S-W, Jorde UP, Jude B, Susen S, Vincentelli A et al (2010) Acquired von Willebrand syndrome after continuous-flow mechanical device support contributes to a high prevalence of bleeding during long-term support and at the time of transplantation. J Am Coll Cardiol 56:1207-1213

19. Crow S, Chen D, Milano C, Thomas W, Joyce L, Piacentino V III et al (2010) Acquired von Willebrand syndrome in continuous-flow ventricular assist device recipients. Ann Thorac Surg 90:1263-1269

20. Meyer AL, Malehsa D, Bara C, Budde U, Slaughter MS, Haverich A et al (2010) Acquired von Willebrand syndrome in patients with an axial flow left ventricular assist device/clinical perspective. Circ Heart Fail 3:675-681
21. Vincentelli A, Susen S, Le Tourneau T, Six I, Fabre O, Juthier F et al (2003) Acquired von Willebrand syndrome in aortic stenosis. N Engl J Med 349:343-349

22. Dandel M, Weng Y, Siniawski H, Stepanenko A, Krabatsch T, Potapov E et al (2011) Heart failure reversal by ventricular unloading in patients with chronic cardiomyopathy: criteria for weaning from ventricular assist devices. Eur Heart J 32:1148-1160

23. Levin HR, Oz MC, Catanese KA, Rose EA, Burkhoff D (1996) Transient normalization of systolic and diastolic function after support with a left ventricular assist device in a patient with dilated cardiomyopathy. J Heart Lung Transplant 15:840-842

24. Birks EJ, Tansley PD, Hardy J, George RS, Bowles CT, Burke M et al (2006) Left ventricular assist device and drug therapy for the reversal of heart failure. N Engl J Med 355:1873-1884

25. Li YY, Feng Y, McTiernan CF, Pei W, Moravec CS, Wang P et al (2001) Downregulation of matrix metalloproteinases and reduction in collagen damage in the failing human heart after support with left ventricular assist devices. Circulation 104:1147-1152

26. Levin HR, Oz MC, Chen JM, Packer M, Rose EA, Burkhoff D (1995) Reversal of chronic ventricular dilation in patients with end-stage cardiomyopathy by prolonged mechanical unloading. Circulation 91:2717-2720

27. Altemose GT, Gritsus V, Jeevanandam V, Goldman B, Margulies KB (1997) Altered myocardial phenotype after mechanical support in human beings with advanced cardiomyopathy. J Heart Lung Transplant 16:765-773 The official publication of the International Society for Heart Transplantation

28. Zafeiridis A, Jeevanandam V, Houser SR, Margulies KB (1998) Regression of cellular hypertrophy after left ventricular assist device support. Circulation 98:656-662

29. Dipla K, Mattiello JA, Jeevanandam V, Houser SR, Margulies KB (1998) Myocyte recovery after mechanical circulatory support in humans with end-stage heart failure. Circulation 97:2316-2322

30. Drews T, Jurmann M, Michael D, Miralem P, Weng Y, Hetzer R (2008) Differences in pulsatile and non-pulsatile mechanical circulatory support in long-term use. J Heart Lung Transplant 27: 1096-1101

31. Hayes HM, Dembo LG, Larbalestier R, O'Driscoll G (2010) Management options to treat gastrointestinal bleeding in patients supported on rotary left ventricular assist devices: a single-center experience. Artif Organs 34:703-706

32. Letsou GV, Pate TD, Gohean JR, Kurusz M, Longoria RG, Kaiser L et al (2010) Improved left ventricular unloading and circulatory support with synchronized pulsatile left ventricular assistance compared with continuous-flow left ventricular assistance in an acute porcine left ventricular failure model. J Thorac Cardiovasc Surg 140:1181-1188

33. Vane JR, Änggård EE, Botting RM (1990) Regulatory functions of the vascular endothelium. N Engl J Med 323:27-36

34. Amir O, Radovancevic B, Delgado RM III, Kar B, Radovancevic $\mathrm{R}$, Henderson $\mathrm{M}$ et al (2006) Peripheral vascular reactivity in patients with pulsatile vs axial flow left ventricular assist device support. J Heart Lung Transplant 25:391-394

35. Westaby S, Bertoni GB, Clelland C, Nishinaka T, Frazier OH (2007) Circulatory support with attenuated pulse pressure alters human aortic wall morphology. J Thorac Cardiovasc Surg 133:575-576

36. Nishimura T, Tatsumi E, Nishinaka T, Taenaka Y, Masuzawa T, Nakata $M$ et al (1999) Diminished vasoconstrictive function caused by long-term nonpulsatile left heart bypass. Artif Organs 23:722-726

37. Mandelbaum I, Burns WH (1965) Pulsatile and nonpulsatile blood flow. JAMA, J Am Med Assoc 191:657-660

38. Wesolowski SA, Sauvage LR, Pinc RD (1955) Extracorporeal circulation: the role of the pulse in maintenance of the systemic circulation during heart-lung by-pass. Surgery 37:663-682 
39. Saito S, Westaby S, Piggot D, Dudnikov S, Robson D, Catarino PA et al (2002) End-organ function during chronic nonpulsatile circulation. Ann Thorac Surg 74:1080-1085

40. Litwak KN, Kihara SI, Kameneva MV, Litwak P, Uryash A, Wu $Z$ et al (2003) Effects of continuous flow left ventricular assist device support on skin tissue microcirculation and aortic hemodynamics. ASAIO J 49:103-107

41. Sezai A, Shiono M, Orime Y, Nakata K-I, Hata M, Nemoto M et al (1996) Comparison studies of major organ microcirculations under pulsatile- and nonpulsatile-assisted circulations. Artif Organs 20:139-142

42. Slaughter MS (2010) Long-term continuous flow left ventricular assist device support and end-organ function: prospects for destination therapy. J Card Surg 25:490-494

43. Pirbodaghi T (2013) We always need a pulse, or do we? J Cardiovasc Transl Res 9:294

44. Radovancevic B, Vrtovec B, de Kort E, Radovancevic R, Gregoric ID, Frazier OH (2007) End-organ function in patients on long-term circulatory support with continuous- or pulsatile-flow assist devices. J Heart Lung Transplant 26:815-818

45. Wieselthaler GM, Riedl M, Schima H, Wagner O, Waldhäusl W, Wolner E et al (2007) Endocrine function is not impaired in patients with a continuous MicroMed-DeBakey axial flow pump. J Thorac Cardiovasc Surg 133:2-6

46. Polska E, Schima H, Wieselthaler G, Schmetterer L (2007) Choroidal microcirculation in patients with rotary cardiac assist device. J Heart Lung Transplant 26:572-578 The official publication of the International Society for Heart Transplantation

47. Kamdar F, Boyle A, Liao K, Colvin-adams M, Joyce L, John R (2009) Effects of centrifugal, axial, and pulsatile left ventricular assist device support on end-organ function in heart failure patients. J Heart Lung Transplant 28:352-359

48. Russell SD, Rogers JG, Milano CA, Dyke DB, Pagani FD, Aranda JM et al (2009) Renal and hepatic function improve in advanced heart failure patients during continuous-flow support with the HeartMate II left ventricular assist device. Circulation 120:2352-2357

49. Chokshi A, Drosatos K, Cheema FH, Ji R, Khawaja T, Yu S et al (2012) Ventricular assist device implantation corrects myocardial lipotoxicity, reverses insulin resistance, and normalizes cardiac metabolism in patients with advanced heart failure/clinical perspective. Circulation 125:2844-2853

50. John R, Mantz K, Eckman P, Rose A, May-Newman K (2010) Aortic valve pathophysiology during left ventricular assist device support. J Heart Lung Transplant 29:1321-1329

51. Cowger J, Pagani FD, Haft JW, Romano MA, Aaronson KD, Kolias TJ (2010) The development of aortic insufficiency in left ventricular assist device-supported patients/clinical perspective. Circ Heart Fail 3:668-674

52. Rose AG, Park SJ, Bank AJ, Miller LW (2000) Partial aortic valve fusion induced by left ventricular assist device. Ann Thorac Surg 70:1270-1274

53. Mudd JO, Cuda JD, Halushka M, Soderlund KA, Conte JV, Russell SD (2008) Fusion of aortic valve commissures in patients supported by a continuous axial flow left ventricular assist device. J Heart Lung Transplant 27:1269-1274 The official publication of the International Society for Heart Transplantation
54. Pak S-W, Uriel N, Takayama H, Cappleman S, Song R, Colombo PC et al (2010) Prevalence of de novo aortic insufficiency during long-term support with left ventricular assist devices. J Heart Lung Transplant 29:1172-1176 The official publication of the International Society for Heart Transplantation

55. Tuzun E, Gregoric ID, Conger JL, Golden K, Jarvik R, Frazier $\mathrm{OH}$ et al (2005) The effect of intermittent low speed mode upon aortic valve opening in calves supported with a Jarvik 2000 axial flow device. ASAIO J 51:139-143

56. Pirbodaghi T, Axiak S, Weber A, Gempp T, Vandenberghe S. Pulsatile control of rotary blood pumps: does the modulation waveform matter? J Thorac Cardiovasc Surg 144:970-977

57. Pirbodaghi T, Weber A, Axiak S, Carrel T, Vandenberghe S (2012) Asymmetric speed modulation of a rotary blood pump affects ventricular unloading. Eur J Cardio-Thorac Surg 43:383-388

58. Bearnson GB, Olsen DB, Khanwilkar PS, Long JW, Allaire PE, Maslen EH (1996) Pulsatile operation of a centrifugal ventricular assist device with magnetic bearings. ASAIO J 42:M620-M623

59. Pirbodaghi T, Weber A, Carrel T, Vandenberghe S (2011) Effect of pulsatility on the mathematical modeling of rotary blood pumps. Artif Organs 35:825-832

60. Shiose A, Nowak K, Horvath DJ, Massiello AL, Golding LAR, Fukamachi K (2010) Speed modulation of the continuous-flow total artificial heart to simulate a physiologic arterial pressure waveform. ASAIO J 56:403-409. doi:10.1097/MAT.0b013e3181e650f8

61. Bourque K, Dague C, Farrar D, Harms K, Tamez D, Cohn W et al (2006) In vivo assessment of a rotary left ventricular assist device-induced artificial pulse in the proximal and distal aorta. Artif Organs 30:638-642

62. Ando M, Takewa Y, Nishimura T, Yamazaki K, Kyo S, Ono M et al (2011) A novel counterpulsation mode of rotary left ventricular assist devices can enhance myocardial perfusion. J Artif Organs 14:185-191

63. Smith RR, Barile L, Cho HC, Leppo MK, Hare JM, Messina E et al (2007) Regenerative potential of cardiosphere-derived cells expanded from percutaneous endomyocardial biopsy specimens. Circulation 115:896-908

64. Miller LW, Pagani FD, Russell SD, John R, Boyle AJ, Aaronson $\mathrm{KD}$ et al (2007) Use of a continuous-flow device in patients awaiting heart transplantation. N Engl J Med 357:885-896

65. Slaughter MS, Myers TJ (2010) Transcutaneous energy transmission for mechanical circulatory support systems: history, current status, and future prospects. J Card Surg 25:484-489

66. Westaby S, Siegenthaler M, Beyersdorf F, Massetti M, Pepper J, Khayat A et al (2010) Destination therapy with a rotary blood pump and novel power delivery. Eur J Cardiothorac Surg 37:350-356

67. Waters BH, Sample AP, Bonde P, Smith JR (2012) Powering a ventricular assist device (VAD) with the free-range resonant electrical energy delivery (FREE-D) system. Proc IEEE 100: 138-149

68. Sample AP, Meyer DA, Smith JR (2011) Analysis, experimental results, and range adaptation of magnetically coupled resonators for wireless power transfer. Ind Electron IEEE Trans 58:544-554

69. Jesty J, Yin W, Perrotta P, Bluestein D (2003) Platelet activation in a circulating flow loop: combined effects of shear stress and exposure time. Platelets 14:143-149 